\title{
Aspir (Carthamus tinctorius L.) Genotiplerinin Fiziksel ve Kimyasal Özelliklerinin Belirlenmesi
}

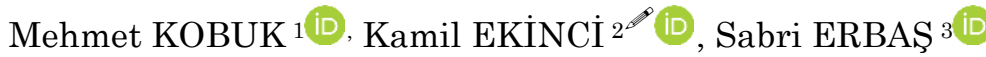

${ }^{1}$ Tarım ve Orman İl Müdürlügü, Isparta, ${ }^{2}$ Isparta Uygulamalı Bilimler Üniversitesi, Tarım Bilimleri ve Teknolojileri Fakültesi, Tarım Makinaları ve Teknolojileri Mühendisliği Bölümü, Isparta, Isparta, ${ }^{3}$ Isparta Uygulamalı Bilimler Üniversitesi,Tarım Bilimleri ve Teknolojileri Fakültesi, Tarla Bitkileri Bölümü, Isparta,

$\bowtie$ : kamilekinci@sdu.edu.tr

\section{ÖZET}

$\mathrm{Bu}$ çalışmada aspir (Carthamus tinctorius L.) genotiplerinin tohumlarının bazı fiziksel ve kimyasal özellikleri (uzunluk, kalınlık, genişlik, geometrik ortalama çap, küresellik, en-boy oranı, tohum yüzey alanı, 1000 tane ağırlı̆̆ı, tohum kabuk kalınlığı, nem içeriği, yığılma açısı, statik sürtünme açısı, renk kroması, renk açısı, kabuk oranı, yağ oranı ve yağ asitleri kompozisyonu) belirlenmiştir. Bu özellikler, hasat, işleme, nakliye, tasnif, ayırma ve paketlemede kullanılan ekipman tasarımı için gereklidir. Çalışmada sekiz aspir hattınin (BAY-ER 1, BAY-ER 2, BAY-ER 5, BAY-ER 6, BAY-ER 12, BAY-ER 15, BAY-ER 16 ve BAY-ER 17) ve beş aspir çeşidinin (Dinçer 5-118, Remzibey 05, Balcı, Linas ve Olası) tohumları kullanılmıştır. Çalışmada aspir hat ve çeşitlerinin fiziksel özelliklerinin büyüklüklerinin benzerlik gösterdiği tespit edilmiştir. Kimyasal özellikleri açısında çalışma değerlendirildiğinde, çeşitler ve hatların yağ içerikleri \%25.78-\%35.16 arasında değişim göstermiştir. En yüksek yağ içeriği BAY-ER 15 (\%35.16) hattında belirlenirken, bunu Olası (\%34.90), Linas (\%34.10) ve BAY-ER 5 (\%33.07) genotipleri takip etmiştir. Olas çeşidi ile BAY-ER 12 ve BAY-ER 16 hatları yüksek oleik asitli genotipler olarak belirlenmiştir.

\author{
Makale Tarihçesi \\ Geliş Tarihi : 28.08.2018
}

Kabul Tarihi : 05.11.2018

\section{Anahtar Kelimeler}

Aspir,

Carthamus tinctorius,

fiziksel ve kimyasal özellikler,

yağ asitleri kompozisyonu

\section{Araştırma Makalesi}

\section{Determination of Yield and Quality Characteristics in Some Maize (Zea mays L.) Varieties}

\section{ABSTRACT}

In this study, some physical and chemical properties (length, thickness, width, geometric mean diameter, sphericity, aspect ratio, seed surface area, seed weight, seed shell thickness, moisture content, angle of repose, static friction coefficient, color value, Hue angle, shell ratio, oil content and composition of fatty acids) of the seeds of safflower (Carthamus tinctorius L.) genotypes were determined. These properties are required for equipment design for mechanization operations such as harvesting, processing, transporting, sorting, sorting and packaging. Seeds of eight safflower lines (BAY-ER 1, BAYER 2, BAY-ER 5, BAY-ER 6, BAY-ER 12, BAY-ER 15, BAY-ER 16 and BAY-ER 17) and five varieties (Dinçer 5-118, Remzibey 05, Balcı, Linas and Olas) were used in the experiment. It has been found that the magnitude of physical properties of safflower lines and varieties were the similar. The oil content of varieties and lines varied between $25.78 \%$ and $35.16 \%$. Olas $(34.90 \%)$. The highest oil content was determined in BAY-ER 15 (35.16\%) line followed by Linas $(34.10 \%)$ and BAY-ER 5 (33.07\%). Olas variety, and BAY-ER 12 and BAY-ER 16 lines was identified as high oleic acid genotypes.

\section{Article History}

Received : 28.8.2018

Accepted : 05.11..2018

\section{Keywords \\ Safflower, \\ Carthamus tinctorius, physical and chemical properties, composition of fatty acids}

\section{Research Article}

To cite: Kobuk M, Ekinci K, Erbaş S 2019. Aspir (Carthamus tinctorius L.) Genotiplerinin Fiziksel ve Kimyasal Özelliklerinin Belirlenmesi. KSÜ Tar Doğa Derg 22(1) :, 89-96, DOI:10.18016/ksutarimdoga.vi.455408.

\section{GİṘŞ}

Aspir (Carthamus tinctorius L.), Compositeae familyasından tek yıllık ve otsu yapıda değerli bir yağ bitkisidir. Aspir bitkisi 80-100 cm arasinda boylanabilen, sarı, beyaz, krem, kırmızı ve turuncu renklerde çiçeklere sahip, kahverengi, beyaz ve üzerinde koyu çizgili beyaz tohumları olan (ender durumlarda siyah), her dalın ucunda içerisinde 
tohumları bulunan küçük tablalar oluşturan bir bitkidir. Aspir, özellikle soğuğa ve sıcağa olan yüksek toleransı nedeniyle kuru tarım alanlarında, tuzluluğa ve yabanci otlara olan toleransi ile de sulu tarım alanlarında değerlendirilebilecek alternatif ürünlerden birisidir (Francois ve Bernstein, 1964; Baydar ve Turgut, 1993). Aspir tohumlarında \%13-46 arasında yağ bulunmakta, bu yağın yaklaşık \%90'ı doymamış yağ asitlerinden (oleik ve linoleik asit) oluşmaktadır (Johnson ve ark., 1999). Bunun yanında aspir tohumları \% 32-34 karbonhidrat, \% 14-15 protein, \% 5-8 nem ve \% 2-7 kül ihtiva etmektedir (Çoşge ve ark., 2007). Yüksek linoleik asit (omega-6) içeriğiyle aspir yağı (\% 70'in üzerinde) özellikle damar sertliği (atherosclerosis) tedavisinde ve yüksek kan kolesterolünün düşürülmesinde kullanılabilecek diyet bitkisel yağlardan birisidir. Margarin, mayonez ve salata yağı üretimi yanında, çabuk kuruma özelliği nedeniyle buruşmaya ve yüksek neme dayanıklı kalitede boya üretiminde de aranan bir maddedir (Knowles, 1989). Aspirin çiçeklerinden elde edilen cartharmin, doğal boya ham maddesi olarak büyük önem taşımaktadır (Nagaraj ve ark., 2001). Ayrıca bitkinin kendisi, yeşil çit ve kuru çiçek olarak kullanılmak üzere aranan değerli bir süs bitkisidir (Çoşge ve ark., 2007). Yağı biyodizel yapımında kullanılırken küspesi de hayvan yemi olarak değerlendirilebilmektedir.

Aspir diğer yağ bitkilerine göre kış ayları serin ve yaz ayları kurak olan bölgelerde adaptasyon yeteneği oldukça yüksek bir bitkidir. Özellikle kurağa ve nispeten de soğuğa olan yüksek toleransı nedeniyle Türkiye'nin kurak ve yarı kurak tarım alanlarında değerlendirilebilecek alternatif ürünlerden birisidir (Uysal ve ark., 2006; Baydar ve Erbaş, 2007). Ülkemizin yağ açığı göz önünde tutulursa, aspir özellikle geniş alanlarda ticari olarak yetiştirilmesi durumunda hem üretici ve hem de sanayici isteklerine cevap verebilecek bir potansiyele sahiptir (Erbaş, 2012).

Biyolojik materyallerin teknik özelliklerinin belirlenmesi, hasat, ekim, dikim, ilaçlama makinalarına kadar tüm tarımsal alet ve makinaların tasarımından, yapımına, çalıştırılmasından verimliliğinin artırılmasına kadar veya depolama, kurutma, ezme, öğütme, paketleme, dondurma gibi hasat sonrası işlemlerin etkin bir şekilde uygulanması gibi pek çok alanda başarılı sonuçlar alınabilmesi için önem taşımaktadır (Husain ve ark., 1971, Mohsenin 1970; Cenkowski ve ark., 1991, Işık 2003). Bu kriterleri dikkate almadan tasarlanan herhangi bir sistem, iş verimliliğini azaltan ve ürün kaybını arttıran yetersiz uygulamalarla sonuçlanır (Akbolat ve ark., 2008). Bu nedenle, aspirin uygun mekanizasyonu için teknik özelliklerinin belirlenmesi herhangi bir ekipmanın tasarımı ve geliştirilmesi için bir ön şarttır (Güzel ve ark., 1999). Son yıllarda çemen otu tohumu
(Altuntaş ve ark., 2005), sarımsak (Haciseferoğulları ve ark., 2005), tek yıllık ve çok yıllık adaçayının (Yılar ve Altuntaş, 2017) besinsel, fiziksel ve teknolojik özellikleri konusunda çalışmalar yapılmıştır. Ancak aspir tohumunun fiziksel ve kimyasal özellikleri hakkında detaylı bir çalışma yayınlanmamıştır.

Bu çalışmada, sekiz aspir hattı ve beş aspir çeşidi (Dinçer 5-118, Remzibey 05, Balcı, Linas ve Olas) tohumlarının fiziksel ve kimyasal özeliklerinin belirlenmesi amaçlanmıştır. Bu bağlamda, uzunluk, kalınlık, genişlik, geometrik ortalama çap, küresellik, en-boy oranı, tohum yüzey alanı, 1000 tane ağırlığı, tohum kabuk kalınlığı, nem içeriği, yığıllma açısı, statik sürtünme açısı, renk kroması, renk açısı, kabuk oranı, yağ oranı ve yağ asitleri kompozisyonu (palmitik, stearik, oleik ve linoleik asit) belirlenmiştir.

\section{MATERYAL ve METOT}

$\mathrm{Bu}$ araştırmada materyal olarak; Anadolu Tarımsal Araştırma Enstitüsü'nden temin edilen Dinçer 5-118, Remzibey-05, Balcı, Linas ve Olas çeşitlerinin tohumları ile Süleyman Demirel Üniversitesi Ziraat Fakültesi Tarla Bitkileri Bölümü tarafından geleneksel olarak kültürü yapılan populasyondan seleksiyonla geliştirilen BAY-ER 1, BAY-ER 2, BAYER 5, BAY-ER 6, BAY-ER 12, BAY-ER 15 (Safir), BAYER 16 ve BAY-ER 17 aspir hatlarindan elde edilen tohumlar kullanılmıştır. Deneysel çalışmalar, Süleyman Demirel Üniversitesi Ziraat Fakültesi Tarım Makineleri ve Teknolojileri Mühendisliği ile Tarla Bitkileri bölümlerinin ilgili laboratuvarlarında yapılmıştır.

Çeşit ve hatların tohumlarının boyut özellikleri (uzunluk, genişlik ve kalınlık) ve kabuk kalınlıklarını (t) belirlemek için 60 adet rastgele seçilen örnekler $0.01 \mathrm{~mm}$ hassasiyetindeki dijital kumpas (Mititoyo) kullanılmıştır. Geometrik ortalama çap, küresellik ve en-boy oranı aşağıdaki eşitlikler ile belirlenmiştir (Mohsenin, 1970; Omobuwajo ve ark., 1999; Kabaş ve ark., 2006).

$$
\begin{aligned}
& \mathrm{D}_{\mathrm{g}}=\mathrm{HWT}^{1 / 3} \\
& \mathrm{~S}_{\mathrm{p}}=\frac{\mathrm{D}_{\mathrm{g}}}{\mathrm{H}} \\
& \mathrm{R}_{\mathrm{a}}=\frac{\mathrm{W}}{\mathrm{H}}
\end{aligned}
$$

Burada;

H : Tohum uzunluğu (mm),

W : Tohum genişliği (mm),

T : Tohum kalınlığ $(\mathrm{mm})$,

$\mathrm{D}_{\mathrm{g}} \quad$ : Geometrik ortalama çap $(\mathrm{mm})$,

$\mathrm{S}_{\mathrm{p}} \quad$ : Küresellik (\%),

$\mathrm{R}_{\mathrm{a}} \quad$ : En-boy oranı

Tohum yüzey alanı (S), Mohsenin (1970), Oyelade ark. (2005), Sacilik ark. (2003) tarafindan sağlanan Eşitlik 4 aracılığı ile hesaplanmıştır.

$$
\mathrm{S}=\pi \mathrm{D}_{\mathrm{g}}^{2}
$$


Tohumlarının yığılma açısı üstü ve altı açık olan boş silindirin yüzeye dik konumda iken tohum ile doldurulduktan sonra dolu silindirin yüzeyden yavaşça kaldırılması sonucu oluşan koninin yüzey ile yaptığı açının (Eşitlik 5) hesaplanmasıyla belirlenmiştir (Kaleemullah ve Gunasekar 2002; Yllar ve Altuntaş, 2017).

$$
\gamma=\tan ^{-1}\left(\frac{2 \mathrm{~h}}{\mathrm{~d}}\right)
$$

Eşitliklerde;

$$
\begin{array}{ll}
\gamma & : \text { Doğal yı̆̆ılma açısı }\left({ }^{\circ}\right), \\
\text { h } & \text { : Koni yüksekliği (cm), } \\
\text { d } & \text { : Koni çapı }(\mathrm{cm}) .
\end{array}
$$

Tohumlarının statik sürtünme katsayllarının belirlenmesinde, 304 paslanmaz çelik sürtünme yüzeyi kullanılmıştır. Yüzeyin üzerinde ölçüleri belli bir kutu içerisinde tohumların eğimi arttırılan yüzeyde kaymaya başladığı andaki açının üçer tekrarlı olacak şekilde derece olarak okunması sonucunda sürtünme katsayısı değerleri (Eşitlik 6) belirlenmiştir (Suthar ve Das 1996; Celik ve ark., 2003; Yılar ve Altuntaş, 2017).

$$
\mu_{\mathrm{s}}=\tan (\Phi)
$$

\section{Eşitlikte}

$\mu_{s} \quad$ : Statik sürtünme katsayısı,

\section{$\Phi \quad:$ : Eğim açısı.}

Tohumların kütleleri $0.001 \mathrm{~g}$ hassasiyetli elektronik terazide tartılarak belirlenmiş, ayrıca üçer tekrarlı 60 ağırlık ölçümü dikkate alınarak 1000 tane ağırlıkları (P) hesaplanmıştır. Yığın hacim ağırlı̆̆ının hesaplanması $\left(\mathrm{H}_{\mathrm{a}}\right)$ için; standart 1 L'lik hektolitre kabı kullanılmıştır. Aspir tohumlarının yaş bazda nem değerinin (N) belirlenmesi için AND MX-50 Model hızlı nem ölçme cihazı (nem terazisi) kullanılmıştır. Renk ölçümleri için Konica MINOLTA marka CR-400 Chroma Meter model renk ölçüm cihazı kullanılmıştır. Her bir çeşit ve hatta ait 60 adet tohumun renk ölçümlerinin ortalamaları alınarak renk değerleri belirlenmiştir. Cihazın gösterdiği L değeri rengin parlaklığını vermektedir. Bu değer renk beyaz ise 0'ı siyah ise 100 '̈̈ göstermektedir. Cihazda okunan a değeri ise rengin kırmızllık ya da yeşillik değerini vermektedir. Cihazda okunan $b$ değeri ise rengin sarılık ya da mavilik oranını vermektedir. Rengin kroması C ile renk açısı (Hue angle) ise a ile gösterilmiştir. C ve a değerleri (Eşitlik 7 ve 8 ) a ve b değerleri kullanılarak hesaplanmıştır (Alibas, 2009).

$$
\begin{aligned}
& C=\sqrt{a^{2}}+\sqrt{b^{2}} \\
& \alpha=\tan ^{-1}\left(\frac{b}{a}\right)
\end{aligned}
$$

Çalışmada ayrıca kabuk oranı (\%), yağ oranı (\%) ve yağ asitleri kompozisyonu incelenmiştir. Tohumların yağ oranı Nükleer Manyetik Rezonans (NMR) cihazında \% olarak okutularak saptanmıştır (Erbaş ve ark, 2016). Yağ asitleri kompozisyonu ise FID detektörlü GC (Shimadzu GC 2010 Plus) cihazında belirlenmiştir. nhekzan ekstraksiyonu ile elde edilen ham yağlar,
Marquard (1987) tarafindan önerilen yöntemle metil esterlerine (FAME) dönüştürülmüş ve aşağıdaki koşullarda GC'ye enjekte edilmiştir. GC cihazının çalışma koşulları; Kolon Teknokroma TR-CN100 (100 $\mathrm{m} \times 0.25 \mathrm{~mm}, 0.20 \mu \mathrm{m}$ ), enjektör sicaklığ $250{ }^{\circ} \mathrm{C}$, detektör sıcaklığ ${ }_{1} 250{ }^{\circ} \mathrm{C}$, akış hızı (psi) 10, taşıyıcı gaz $\mathrm{N}(40 \mathrm{~mL} /$ dakika $)$, enjektör kapasitesi $1.0 \mu \mathrm{L}$ 'dir. Firın sıcaklığı $140{ }^{\circ} \mathrm{C}$ 'de 10 dakika bekledikten $240{ }^{\circ} \mathrm{C}$ 'e dakika $3{ }^{\circ} \mathrm{C}$ 'lik artışla ulaşmış ve bu sıcaklıkta 10 dakika bekletilmiştir. Elde edilen kromotogramlardaki pikler ticari standart yağ asidi metil ester karışımına (Sigma, Supelco ${ } \quad 37$ Component FAME Mix) göre isimlendirilmiştir.

\section{BULGULARI ve TARTIŞMA}

Aspir hat ve çeşit tohumlarının uzunluk, genişlik, kalınlık, geometrik ortalama çap, küresellik, en-boy oranı, yüzey alanı, 1000 tane ağırlığı ve hacim ağırlığı özellikleriyle ilişkili araştırma bulguları Çizelge 1'de verilirken, tohum kabuk kalınlığı, nem içeriği, doğal yığılma açısı, statik sürtünme katsayısı ve renk parametreleri (L, a, b, C ve $\alpha$ ) Cizelge 2'de verilmiştir. Aspir hatlarının tohum uzunlukları 7.18-8.13 mm arasında değişirken çeşitlerin tohum uzunlukları 7.37$8.35 \mathrm{~mm}$ arasında değişmiştir. Hatlar arasında en kısa tohum uzunluğu BAY-ER 12'de ölçülürken en uzun ise BAY-ER 6'da ölçülmüştür. Çeşitler arasında ise en kısa ve en uzun tohumlar sırasıyla Dinçer 5-118 (7.37 $\mathrm{mm})$ ve Olas $(8.35 \mathrm{~mm})$ çeşitlerinde tespit edilmiştir. Genişlik değerleri hatlarda 4.05-4.41 mm arasında, çeşitlerde ise $3.90-4.33 \mathrm{~mm}$ arasında değişmiştir (Çizelge 1). Tohum kalınlık değerleri hatlarda 3.31$3.69 \mathrm{~mm}$ arasında, çeşitlerde ise $3.24^{-} 3.68 \mathrm{~mm}$ arasında değiştiği tespit edilmiştir (Çizelge 1). Tohumların geometrik boyutlarından hesaplanan geometrik ortalama çaplar hatlarda 4.58-5.06 mm olarak ölçülmüştür. Çeşitlerin geometrik çap değerleri ise $4.64^{-} 5.08 \mathrm{~mm}$ arasında değişmiştir (Çizelge 1). Nesnenin biçim özelliğini aynı yuvarlaklıkta kürenin biçim özelliğine göre ifadesi olan küresellik değeri (Tunalıgil, 1993), aspir hatlarında \%60.94-\%65.90 arasında değişirken, çeşitlerde ise \%56.93-\%65.82 arasında değişmiştir (Çizelge 1). En-boy oranı, tohum genişliği ile meyvenin uzunluğu arasında bir ilişki sağlar ve bu şeklin uzunlamasına olma eğiliminin bir göstergesidir (Omobuwajo ve ark., 1999). En-boy oranı aspir hatlarında 0.53-0.60 arasında, aspir çeşitlerinde ise 0.47-0.59 arasında değişmiştir (Çizelge 1). Geometrik ortalama çap üzerinden hesaplanan tohum yüzey alanı aspir hatlarında $65.99-80.86 \mathrm{~mm}^{2}$ arasında, aspir çeşitlerinde ise $65.92-81.33 \mathrm{~mm}^{2}$ arasında değişmiştir (Çizelge 1). Benzer bir şekilde, Çalışır ark. (2005)'nın yapmış olduğu çalışmada, \% 5.61 nem içeriğine sahip aspir tohumlarının (çeşit bildirilmemiş) uzunluk, genişlik, kalınlık, geometrik ortalama çap ve küresellik değerleri $6.89 \mathrm{~mm}, 3.76$ $\mathrm{mm}, 2.71 \mathrm{~mm}, 4.13 \mathrm{~mm}$ ve \% 60 olarak belirlenmiştir. 
Aspir hatlarının hacim ağırlıkları 452.97-602.37 g/L arasında değişirken, aspir çeşitlerinin hacim ağırlığı 548.80-580.87 g/L arasında değişmiştir. Benzer bir şekilde, Çalışır ark. (2005)'nın yapmış olduğu çalışmada, \% 5.61 nem içeriğine sahip aspir tohumlarının hacim ağırlığ belirlenmiştir. Dinçer 5-118 çeşidinin 1000 tane ağırlığ 42.40 g'dır. 4 hattın (BAY-ER 2, BAY-ER 6, BAY-ER 16 ve BAY-ER 17) 1000 tohum ağırlığı diğer ebeveynleri ve çeşitlere göre daha yüksek iken 1 hat (BAY-ER 12) daha düşük değer göstermiştir. En yüksek 1000 tohum ağırlığı BAY-ER 6 hattında belirlenmiş (49.10 g), bunu BAY-ER 17 (44.90 g), BAYER 16 (44.85 g) ve BAY-ER 1 (44.10 g) hatları takip etmiştir (Çizelge 1). Weiss (2000) aspirde 1000 tane ağırlığının 50 g'a çıkarılmasının tohum ve/veya yağ verimini artırabileceğini bildirmiştir. Diğer araştırmalarda; Çelikoğlu (2004) 1000 tane ağırlığının 33.9-61.7 g arasında, Erbaş (2007) 33.6-52.1 g arasında ve Safavi ark. (2011) 17.8-46.0 g arasında değiştiğini bildirmiştir.

Çalışmada aspir hatlarının tohum kabuk kalınlıkları ölçümlerinin 0.28-0.37 $\mathrm{mm}$ arasında, çeşitlerin tohum kabuğu kalınlıkları ise $0.30-0.35 \mathrm{~mm}$ arasında değiştiği tespit edilmiştir. Aspir hat tohumlarının nem değerleri yaş bazda \%3.47-4.03 arasında ölçülmüş olup çeşitlerin ise \%3.07-4.04 arasında değiştiği belirlenmiştir (Çizelge 2). Aspir hatlarına ait doğal yığılma açıları $24.20^{\circ}-26.23^{\circ}$ arasında değişirken aspir çeşitlerine ait doğal yığılma açıları $23.17^{\circ}-25.97^{\circ}$ arasında değişmiştir. Statik sürtünme açısı değeri 304 paslanmaz çelik yüzeyde tespit edilmiş olup aspir hatları için değeri 0.33-0.43 olarak, ölçülmüştür. Bu değerler aspir çeşitleri için 0.36-0.44 olarak tespit edilmiştir. Benzer bir şekilde, Çalışır ark. (2005)'nın yapmış olduğu çalışmada, \% 5.61 nem içeriğine sahip aspir tohumlarının metal levha üzerinde statik sürtünme katsayısını yaklaşık 0.47 olarak belirlemişlerdir. Aspir hatlarının C değeri 9.89-10.94 olarak ölçülmüştür. Çeşitlerin ise 9.88- 12.28 arasında değişmiştir (Çizelge 2). Aspir hatlarının $\alpha$ değeri 68.10-70.20 olarak ölçülmüştür. Çeşitlerin ise 69.4171.24 arasında değişmiştir (Çizelge 2).

Aspir çeşit ve hatlarının kabuk oranı, yağ oranı ve yağ asitleri ortalamaları Çizelge 3’te verilmiştir. Çalışmada en düşük ve en yüksek kabuk oranına sahip aspir çeşitleri Linas (43.19 ve Remzibey-05 (\%52.90) olarak belirlenirken aspir hatları arasında en düşük ve en yüksek kabuk oranı BAY-ER 15 (\%42.68) ve BAYER 6 (\%50.98) hatlarında tespit edilmiştir (Çizelge 3). Aspir diğer yağ bitkilerine (ayçiçeği, kanola, yerfistığı, susam) göre daha düşük bir yağ oranına sahiptir. Çeşitler ve hatların yağ içerikleri \%25.78-35.16 arasında değişim göstermiştir. En yüksek yağ içeriği BAY-ER 15 hattında belirlenirken, bunu Olas (\%34.90), Linas (\%34.10) ve BAY-ER 5 (\%33.07) genotipleri takip etmiştir. En düşük yağ oranı ise
\%25.78 ile Dinçer 5-118 çeşidinde kaydedilmiştir (Çizelge 3). Aspir hat ve çeşitlerinin yağ asitleri kompozisyonu Çizelge 3 te sunulmuştur. Aspirde yağ oranı ile kabuk oranı arasında olumsuz yönde önemli bir ilişki vardır; kabuk oranı azaldıkça yağ oranı artmaktadır (Knowles, 1969).

GC-FID sonuçlarına göre aspir yağının en önemli yağ asitlerinin doymuş yağ asitlerinden palmitik asit (C16:0) ve stearik asit (C18:0), doymamış yă asitlerinden oleik asit (C18:1) ve linoleik asit (C18:2) olduğu tespit edilmiştir. Çeşit ve hatların palmitik asit içeriği \%4.64-8.91, stearik asit içeriği \%1.62-3.07, oleik asit içeriği \%8.06-71.21 ve linoleik asit içeriği \%23.1883.04 arasında değişmiştir (Çizelge 3). Dinçer 5-118 çeşidi yüksek linoleik asit oranı (\%83.04) ile ve Olas çeşidi yüksek oleik asit içeriği (\%67.09) ile öne çıkmıştır.

\section{SONUÇ}

Bu çalışmada sekiz aspir hattı (BAY-ER 1, BAY-ER 2, BAY-ER 5, BAY-ER 6, BAY-ER 12, BAY-ER 15, BAYER 16 ve BAY-ER 17) ve beş aspir çeşidinin (Dinçer 5118, Remzibey 05, Balcı, Linas ve Olas) fiziksel ve kimyasal özelikleri belirlenmiştir. $\mathrm{Bu}$ özellikler uzunluk, kalınlık, genişlik, geometrik ortalama çap, küresellik, en-boy oranı, tohum yüzey alanı, 1000 tane ağırlığı, tohum kabuk kalınlı̆̆g, nem içeriği, yığılma açısı, statik sürtünme açısı, renk kroması, renk açısı, kabuk oranı, yağ oranı ve yă asitleri kompozisyonudur (palmitik, stearik, oleik ve linoleik asit). Çalışmada aspir hatları ile çeşitlerin fiziksel özelliklerin değerleri birbirine yakın olduğu tespit edilmiştir. Çalışmada en düşük ve en yüksek kabuk oranına sahip aspir çeşitleri Linas (43.19 ve Remzibey05 (\%52.90) olarak belirlenirken aspir hatları arasında en düşük ve en yüksek kabuk oranı BAY-ER 15 (\%42.68) ve BAY-ER 6 (\%50.98) hatlarmda tespit edilmiştir. Çeşitler ve hatların yağ içerikleri \%25.7835.16 arasında değişim göstermiştir.

En yüksek yă̆ içeriği BAY-ER 15 hattında belirlenirken, bunu Olas (\%34.90), Linas (\%34.10) ve BAY-ER 5 (\%33.07) genotipleri takip etmiştir. En düşük yağ oranı ise \%25.78 ile Dinçer 5-118 çeşidinde kaydedilmiştir. BAY-ER 12 ve BAY-ER 16 hatları ile Olas çeşidi yüksek oleik asitli genotipler olarak belirlenmiştir.

\section{TEŞEKKÜR}

Çalışmada maddi destek sağlayan, Bilimsel Araştırma Projeleri Koordinasyon Birimine, Araştırmada yardımlarını esirgemeyen Prof. Dr. Hasan BAYDAR'a ve Araştırma Görevlisi İsmail BOYAR ile Barbaros Salih KUMBUL’a teşekkür ederiz. 
Çizelge 1. Aspir hatlarına ve çeşitlere ait tohumların uzunluk $(\mathrm{H})$, genişlik $(\mathrm{W})$, kalınlık $(\mathrm{T})$, geometrik ortlama çap $\left(\mathrm{D}_{\mathrm{g}}\right)$, küresellik $\left(\mathrm{S}_{\mathrm{p}}\right)$, en-boy oranı $\left(\mathrm{R}_{\mathrm{a}}\right)$, yüzey alanı $(\mathrm{S})$, hacim ağırlı̆̆g $\left(\mathrm{H}_{\mathrm{a}}\right)$ ve 1000 tane ağırlığı $(\mathrm{P})$ değerleri

\begin{tabular}{|c|c|c|c|c|c|c|c|c|c|}
\hline Çeşit/hat & $\mathrm{H}(\mathrm{mm})$ & $\mathrm{W}(\mathrm{mm})$ & $\mathrm{T}(\mathrm{mm})$ & $\mathrm{D}_{\mathrm{g}}(\mathrm{mm})$ & $\mathrm{S}_{\mathrm{p}}(\%)$ & $\mathrm{R}_{\mathrm{a}^{-}}$ & $\mathrm{S}\left(\mathrm{mm}^{2}\right)$ & $\mathrm{H}_{\mathrm{a}}(\mathrm{g} / \mathrm{L})$ & $\mathrm{P}(\mathrm{g})$ \\
\hline BAY-ER 1 & $7.49 \pm 0.48$ & $4.12 \pm 0.30$ & $3.34 \pm 0.30$ & $4.69 \pm 0.29$ & $62.62 \pm 2.59$ & $0.55 \pm 0.04$ & $69.19 \pm 8.64$ & $546.03 \pm 8.73$ & $44.10 \pm 0.99$ \\
\hline BAY-ER 2 & $7.38 \pm 0.48$ & $4.41 \pm 0.37$ & $3.53 \pm 0.29$ & $4.86 \pm 0.29$ & $65.90 \pm 3.28$ & $0.60 \pm 0.05$ & $74.32 \pm 8.80$ & $564.13 \pm 7.26$ & $43.75 \pm 2.47$ \\
\hline BAY-ER 5 & $7.56 \pm 0.47$ & $4.15 \pm 0.29$ & $3.40 \pm 0.26$ & $4.74 \pm 0.28$ & $62.78 \pm 2.21$ & $0.55 \pm 0.03$ & $70.83 \pm 8.26$ & $566.03 \pm 8.37$ & $41.15 \pm 0.21$ \\
\hline BAY-ER 6 & $8.13 \pm 0.55$ & $4.34 \pm 0.32$ & $3.69 \pm 0.36$ & $5.06 \pm 0.34$ & $62.35 \pm 2.82$ & $0.54 \pm 0.04$ & $80.86 \pm 10.93$ & $602.37 \pm 3.00$ & $49.10 \pm 0.28$ \\
\hline BAY-ER 12 & $7.18 \pm 0.42$ & $4.05 \pm 0.26$ & $3.31 \pm 0.26$ & $4.58 \pm 0.23$ & $63.85 \pm 2.73$ & $0.57 \pm 0.04$ & $65.99 \pm 6.73$ & $542.10 \pm 8.02$ & $31.15 \pm 0.07$ \\
\hline BAY-ER 15 & $7.45 \pm 0.52$ & $4.20 \pm 0.33$ & $3.46 \pm 0.28$ & $4.76 \pm 0.33$ & $63.97 \pm 2.41$ & $0.56 \pm 0.03$ & $71.57 \pm 9.91$ & $545.13 \pm 3.71$ & $38.65 \pm 0.92$ \\
\hline BAY-ER 16 & $7.88 \pm 0.56$ & $4.16 \pm 0.30$ & $3.37 \pm 0.24$ & $4.79 \pm 0.27$ & $60.94 \pm 3.03$ & $0.53 \pm 0.04$ & $72.37 \pm 8.15$ & $590.97 \pm 6.11$ & $44.85 \pm 1.77$ \\
\hline BAY-ER 17 & $7.80 \pm 0.61$ & $4.41 \pm 0.28$ & $3.61 \pm 0.29$ & $4.98 \pm 0.30$ & $64.05 \pm 3.10$ & $0.57 \pm 0.04$ & $78.24 \pm 9.43$ & $595.00 \pm 6.39$ & $44.90 \pm 2.40$ \\
\hline Dinçer 5-118 & $7.37 \pm 0.51$ & $4.33 \pm 0.39$ & $3.58 \pm 0.36$ & $4.85 \pm 0.36$ & $65.82 \pm 3.65$ & $0.59 \pm 0.05$ & $74.11 \pm 11.19$ & $580.87 \pm 3.41$ & $42.40 \pm 6.08$ \\
\hline Remzibey-05 & $8.31 \pm 0.59$ & $4.29 \pm 0.35$ & $3.68 \pm 0.34$ & $5.08 \pm 0.36$ & $61.15 \pm 2.78$ & $0.52 \pm 0.04$ & $81.33 \pm 11.47$ & $576.37 \pm 10.51$ & $41.60 \pm 2.12$ \\
\hline Balcı & $7.57 \pm 0.42$ & $3.99 \pm 0.30$ & $3.32 \pm 0.20$ & $4.64 \pm 0.24$ & $61.39 \pm 2.62$ & $0.53 \pm 0.04$ & $67.85 \pm 6.99$ & $555.90 \pm 2.78$ & $40.20 \pm 1.56$ \\
\hline Linas & $7.72 \pm 0.54$ & $4.04 \pm 0.35$ & $3.27 \pm 0.29$ & $4.67 \pm 0.33$ & $60.56 \pm 2.37$ & $0.52 \pm 0.04$ & $68.81 \pm 9.60$ & $537.07 \pm 10.56$ & $43.85 \pm 0.64$ \\
\hline Olas & $8.35 \pm 0.48$ & $3.90 \pm 0.34$ & $3.29 \pm 0.28$ & $4.75 \pm 0.28$ & $56.93 \pm 2.99$ & $0.47 \pm 0.04$ & $70.95 \pm 8.31$ & $548.80 \pm 1.55$ & $42.40 \pm 0.00$ \\
\hline
\end{tabular}

Çizelge 2. Aspir hatlarına ve çeşitlerine ait tohumların kabuk kalınlığı $(\mathrm{t})$, nem içeriği $(\mathrm{N})$, doğal yığılma açısı $(\gamma)$, statik sürtünme katsayısı ( $\left.\mu_{\mathrm{s}}\right)$ ve renk parametrelerinin (L (parlaklık), a (kırmızılık/yeşillik), b (sarılık/mavilik), C (kroma) ve $\alpha$ (açı)) değişimi

\begin{tabular}{|c|c|c|c|c|c|c|c|c|c|}
\hline Çeşit/hat & $\mathrm{t}(\mathrm{mm})$ & $\mathrm{N}(\%)$ & $\gamma\left({ }^{\circ}\right)$ & $\mu_{\mathrm{s}^{-}}$ & $\mathrm{L}^{-}$ & $a^{-}$ & $b^{-}$ & $\mathrm{C}-$ & $\alpha\left(^{\circ}\right)$ \\
\hline BAY-ER 1 & $0.31 \pm 0.04$ & $4.03 \pm 0.06$ & $26.20 \pm 0.17$ & $0.37 \pm 0.02$ & $67.81 \pm 3.55$ & $3.55 \pm 0.36$ & $9.73 \pm 1.29$ & $10.36 \pm 1.30$ & $69.84 \pm 1.80$ \\
\hline BAY-ER 2 & $0.28 \pm 0.04$ & $3.53 \pm 0.04$ & $25.17 \pm 0.23$ & $0.33 \pm 0.02$ & $67.56 \pm 3.82$ & $3.54 \pm 0.43$ & $9.23 \pm 1.39$ & $9.89 \pm 1.40$ & $68.83 \pm 2.28$ \\
\hline BAY-ER 5 & $0.30 \pm 0.03$ & $3.61 \pm 0.10$ & $25.17 \pm 0.40$ & $0.38 \pm 0.04$ & $66.95 \pm 4.18$ & $3.53 \pm 0.47$ & $9.43 \pm 1.61$ & $10.08 \pm 1.62$ & $69.28 \pm 2.37$ \\
\hline BAY-ER 6 & $0.29 \pm 0.04$ & $3.65 \pm 0.14$ & $26.13 \pm 0.25$ & $0.35 \pm 0.02$ & $65.76 \pm 3.15$ & $3.86 \pm 0.33$ & $10.12 \pm 1.09$ & $10.84 \pm 1.08$ & $69.03 \pm 1.90$ \\
\hline BAY-ER 12 & $0.29 \pm 0.03$ & $3.68 \pm 0.10$ & $24.20 \pm 0.44$ & $0.43 \pm 0.12$ & $67.34 \pm 3.79$ & $3.41 \pm 0.42$ & $9.30 \pm 1.59$ & $9.91 \pm 1.59$ & $69.61 \pm 2.48$ \\
\hline BAY-ER 15 & $0.31 \pm 0.06$ & $3.62 \pm 0.04$ & $25.87 \pm 0.64$ & $0.35 \pm 0.03$ & $66.79 \pm 3.50$ & $3.42 \pm 0.40$ & $10.35 \pm 7.47$ & $10.94 \pm 7.41$ & $70.20 \pm 2.99$ \\
\hline BAY-ER 16 & $0.37 \pm 0.05$ & $3.62 \pm 0.26$ & $25.60 \pm 0.30$ & $0.37 \pm 0.05$ & $66.61 \pm 4.13$ & $3.80 \pm 0.49$ & $9.55 \pm 1.44$ & $10.29 \pm 1.45$ & $68.10 \pm 2.60$ \\
\hline BAY-ER 17 & $0.35 \pm 0.06$ & $3.47 \pm 0.09$ & $26.23 \pm 0.50$ & $0.35 \pm 0.03$ & $65.11 \pm 3.54$ & $3.74 \pm 0.51$ & $9.81 \pm 1.57$ & $10.51 \pm 1.61$ & $68.94 \pm 2.19$ \\
\hline Dinçer 5-118 & $0.31 \pm 0.06$ & $3.62 \pm 0.30$ & $23.17 \pm 0.81$ & $0.39 \pm 0.03$ & $67.41 \pm 3.99$ & $3.64 \pm 0.37$ & $9.76 \pm 1.33$ & $10.42 \pm 1.35$ & $69.41 \pm 1.70$ \\
\hline Remzibey-05 & $0.35 \pm 0.05$ & $4.04 \pm 0.26$ & $25.53 \pm 0.60$ & $0.36 \pm 0.03$ & $67.62 \pm 4.23$ & $3.80 \pm 0.43$ & $9.11 \pm 1.35$ & $9.88 \pm 1.36$ & $67.15 \pm 2.36$ \\
\hline Balcı & $0.30 \pm 0.05$ & $3.57 \pm 0.09$ & $25.10 \pm 0.53$ & $0.44 \pm 0.08$ & $66.21 \pm 3.88$ & $3.73 \pm 0.51$ & $10.04 \pm 1.47$ & $10.72 \pm 1.49$ & $69.45 \pm 2.44$ \\
\hline Linas & $0.32 \pm 0.06$ & $3.48 \pm 0.26$ & $24.87 \pm 0.91$ & $0.38 \pm 0.06$ & $65.21 \pm 4.14$ & $3.65 \pm 0.37$ & $10.83 \pm 1.27$ & $11.44 \pm 1.27$ & $71.24 \pm 2.04$ \\
\hline Olas & $0.30 \pm 0.06$ & $3.07 \pm 0.27$ & $25.97 \pm 0.55$ & $0.37 \pm 0.03$ & $63.65 \pm 4.78$ & $3.97 \pm 0.48$ & $11.62 \pm 1.46$ & $12.28 \pm 1.49$ & $71.05 \pm 1.88$ \\
\hline
\end{tabular}


Çizelge 3. Aspir hatlarına ve çeşitlerine ait tohumların kabuk oranı, yağ oranı ve yağ asitleri ortalamaları

\begin{tabular}{|c|c|c|c|c|c|c|}
\hline Çeşit/hat & Kabuk oranı $(\%)$ & Yağ oranı $(\%)$ & Palmitik asit(\%) & Stearik asit(\%) & Oleik asit(\%) & Linoleik asit(\%) \\
\hline BAY-ER 1 & $47.79 \pm 0.80$ & $31.14 \pm 0.41$ & $6.18 \pm 0.39$ & $2.09 \pm 0.08$ & $35.54 \pm 2.11$ & $55.66 \pm 2.12$ \\
\hline BAY-ER 2 & $48.78 \pm 4.13$ & $31.20 \pm 0.63$ & $6.07 \pm 0.71$ & $2.71 \pm 0.71$ & $45.05 \pm 0.71$ & $45.84 \pm 0.71$ \\
\hline BAY-ER 5 & $45.14 \pm 7.12$ & $33.07 \pm 1.5$ & $6.81 \pm 0.71$ & $2.56 \pm 0.71$ & $29.65 \pm 0.71$ & $60.73 \pm 0.71$ \\
\hline BAY-ER 6 & $50.98 \pm 0.33$ & $29.33 \pm 0.42$ & $8.91 \pm 0.71$ & $1.69 \pm 0.71$ & $27.44 \pm 1.41$ & $61.70 \pm 1.41$ \\
\hline BAY-ER 12 & $46.04 \pm 4.79$ & $32.14 \pm 0.64$ & $4.64 \pm 0.71$ & $2.45 \pm 0.71$ & $71.21 \pm 1.41$ & $21.29 \pm 1.41$ \\
\hline BAY-ER 15 & $42.68 \pm 0.53$ & $35.16 \pm 0.85$ & $5.66 \pm 0.71$ & $2.91 \pm 0.71$ & $30.48 \pm 1.41$ & $62.60 \pm 1.41$ \\
\hline BAY-ER 16 & $45.89 \pm 1.86$ & $30.53 \pm 1.00$ & $5.35 \pm 0.00$ & $2.07 \pm 0.00$ & $59.03 \pm 1.41$ & $33.21 \pm 1.41$ \\
\hline BAY-ER 17 & $48.38 \pm 4.50$ & $30.68 \pm 1.37$ & $5.02 \pm 1.41$ & $3.07 \pm 0.71$ & $41.62 \pm 1.41$ & $42.02 \pm 2.27$ \\
\hline Dinçer 5-118 & $52.77 \pm 0.10$ & $25.78 \pm 0.09$ & $4.96 \pm 0.71$ & $1.62 \pm 0.71$ & $8.06 \pm 1.41$ & $83.04 \pm 1.41$ \\
\hline Remzibey-05 & $52.90 \pm 2.26$ & $28.73 \pm 1.35$ & $5.83 \pm 0.71$ & $2.38 \pm 0.71$ & $13.35 \pm 1.41$ & $78.24 \pm 1.41$ \\
\hline Balcı & $45.44 \pm 3.46$ & $32.67 \pm 3.48$ & $6.80 \pm 0.71$ & $2.40 \pm 0.71$ & $11.46 \pm 0.71$ & $79.17 \pm 0.71$ \\
\hline Linas & $43.19 \pm 0.58$ & $34.10 \pm 0.82$ & $6.32 \pm 0.71$ & $2.92 \pm 0.71$ & $16.68 \pm 1.41$ & $73.83 \pm 1.41$ \\
\hline Olas & $43.35 \pm 2.91$ & $34.90 \pm 0.07$ & $5.15 \pm 0.70$ & $2.23 \pm 0.71$ & $67.09 \pm 3.54$ & $23.18 \pm 0.71$ \\
\hline
\end{tabular}




\section{KAYNAKÇA}

Akbolat D, Ertekin C, Menges HO, Ekinci K, Erdal I 2008. Physical and Nutritional Properties of Jujube (Zizyphus jujuba Mill.) Growing in Turkey. Asian Journal of Chemistry, 20(1): 757-766.

Alibas I 2009. Microwave, Vacuum, and Air Drying Characteristics of Collard Leaves. Drying Technology, 27(11): 1266-1273.

Altuntas E, Ozgoz E, Taser ÖF 2005. Some physical properties of fenugreek (Trigonella foenumgraceum L.) seeds. Journal of Food Engineering, 71(1): 37-43.

Baydar H, Erbaş S 2007. Türkiye'de Yemeklik Yağ ve Biyodizel Üretimine Uygun Aspir Islahı. I. Ulusal Yağlı Tohumlu Bitkiler ve Biyodizel Sempozyumu. 28-31 Mayıs, 378-386, Samsun.

Baydar H, Turgut İ 1993. Aspirin (Carthamus tinctorius L.)'in Antalya Koşullarında Kışlık Olarak Yetiştirme Olanakları Üzerine Araştırmalar. Akdeniz Üniversitesi Ziraat Fakültesi Dergisi, 5-6 (1-2): 75-92.

Celik A, Ercisli S, Turgut N 2007. Some Physical, Pomological and Nutritional Properties of Kiwifruit cv. Hayward. International Journal of Food Sciences and Nutrition, 58(6): 411-418.

Cenkowski S, Bielewicz J, Britton MG 1991. A Single Kernel Creep and Recoveri Test. Transactions of the ASAE, 34(6): 2484-2490.

Çalışır S, Marakoğlu T, Öztürk Ö, Öğüt H 2005. Some Physical Properties of Safflower Seed (Carthamus Tinctorius L.). Selçuk Tarım ve Gıda Bilimleri Dergisi, 19(36): 87-92.

Çelikoğlu F 2004. Eskişehir Koşullarında Geliştirilen Aspir (Carthamus Tinctorius L.) Hatlarında Verim Kriterlerinin Belirlenmesi. Ankara Üniversitesi Tarla Bitkileri Anabilim Dalı, Yüksek Lisans Tezi, $78 \mathrm{~s}$.

Çoşge B, Gürbüz B, Kıralan M 2007. Oil Content and Fatty Acid Composition of Some Safflower (Carthamus Tinctorius L.) Varieties Sown in Spring and Winter. International Journal of Natural and Engineering Sciences, 1(3): 11-15.

Erbaş S 2007. Aspirde (Carthamus Tinctorius L.) Sentetik Erkek Kısırlığı Tekniği ile Elde Edilmiş Melez Popülasyonlarından Hat Geliştirme Olanakları. SDÜ Fen Bilimleri Enstitüsü, Yüksek Lisans Tezi, $93 \mathrm{~s}$.

Erbaş S 2012. Melezleme Islahı ile Tohum Verimi, Yağ ve Oleik Asit İçeriği Yüksek Aspir (Carthamus Tinctorius L.) Hatlarının Geliştirilmesi. SDÜ Fen Bilimleri Enstitüsü, Doktora Tezi, $132 \mathrm{~s}$.

Erbaş S, Tonguç M, Şanlı A 2016. Variations in The Agronomic and Quality Characteristics of Domestic And Foreign Safflower (Carthamus Tinctorius L.) Genotypes. Turkish Journal of Field Crops, 21(1):110-119.

Francois LE, Bernstein L 1964. Salt Tolerance of Safflower. Agron. J., 56(1): 38-40.
Guzel E, Ulger P, Kayisoglu B. 1999. Urun Isleme ve Degerlendirme Teknigi. Cukurova Universitesi Ziraat Fakultesi Genel Yayın No:145, Adana.

Haciseferogullari H, Ozcan M, Demir F, Calisir S 2005. Some Nutritional and Technological Properties of Garlic. Journal of Food Engineering, 68(4): 463-469.

Husain A, Agrawal KK, Ojha TP, Bhole NG 1971. Viscoelastic Behavior of Rough Rice. Transactions of the ASAE, 14(2): 313-318.

Işık E 2003. Biyolojik Materyalin Teknik Özellikleri. U. Ü. Ziraat Fak. Ders Notları No: 95, Bursa,105s.

Johnson RC, Bergman JW, Flynn CR 1999. Oil and Meal Characteristics of Core and Non-core Safflower Accessions from the USDA Collection. Genet. Res. Crop Evol., 46(6): 611-618.

Kabaş O, Ozmerzi A, Akinci I 2006. Physical Properties of Cactus Pear (Opuntia ficus india L.) Grown Wild in Turkey. Journal of Food Engineering 73(2): 198-202.

Kaleemullah S, Gunasekar JJ 2002. MoistureDependet Physical Properties of Arecanut Trues. Biosystem Engineering, 82: 331-338.

Knowles 1989. Safflower. (Oil crops of the World McGraw-Hill, New York): Eds, Downey R, Röbbelen K, Ashri GA) 363-374.

Knowles PF 1969. Modification of Quantity and Quality of Safflower Oil Through Plant Breeding. Journal of the American Oil Chemists' Society, 46(3): 130-132.

Marquard R 1987. Qualitatsanalytik im dienste der ölpflanzenzüchtung. Fat Science Technology, 89: 95-99.

Mohsenin NN 1970. Physical Properties of Plant and Animal Materials: Structure, Physical Characteristics and Mechanical Properties. Gordon and Breach Science Publisher, New York, 742p.

Nagaraj G, Devi GN, Srinivas CVS 2001. Safflower Petals and Their Chemical Composition. Proc. V. International Safflower Conference, 23-27 July, USA.

Omobuwajo TO, Akande EA, Sanni L A 1999. Selected Physical, Mechanical And Aerodynamic Properties of African Breadfruit (Treculia Africana) Seeds. Journal of Food Engineering, 40(4): 241-244.

Oyelade OJ, Odugbenro PO, Abioye AO, Raji NL 2005 Some Physical Properties of African Star Apple Seeds. Journal of Food Engineering, 67(4): 435-440.

Sacilik, K., Ozturk, R., Keskin, R., 2003. Some Physical Properties of Hemp Seed. Biosystems Engineering, 86(2): 191-198.

Safavi S A, Pourdad S S, Safavi SM, Safavi A S 2011. Heritability and Genetic Gain of Some Morphological Traits in Safflower (Carthamus Tinctorius L.). American Journal of Scientific Research, 17: 14-18.

Suthar SH, Das SK 1996. Some Physical Properties of Karingda [Citrus Lanatus (Thumb) Mansf] Grains. 
Journal of Agricultural Engineering Research, 65(1): 15-22.

Tunalıgil BG 1993. Biyolojik Malzemelerin Teknik Özellikleri. AÜ Ziraat Fakültesi Yayınları No: 1305 Ankara, 136s.

Uysal N, Baydar H, Erbaş, S 2006. Isparta Populasyonundan Geliştirilen Aspir (Carthamus Tinctorius L.) Hatlarının Tarımsal ve Teknolojik
Özelliklerinin Belirlenmesi. SDÜ Ziraat Fakültesi Dergisi, 11(1): 52-63.

Weiss EA 2000. Oilseed Crops. Blackwell Sci. Ltd., Victoria, Australia, 364p.

Yılar M, Altuntaş E 2017. Tek Yıllık ve Çok Yıllık Adaçayı (Salvia Viridis L., Salvia Cryptantha Montbret Et Aucher) Tohumlarının Bazı Fiziksel Özelliklerinin Belirlenmesi. Akdeniz Üniversitesi Ziraat Fakültesi Dergisi, 30(2): 137-141. 